\title{
GW23-e2718 SLEEP DISTURBANCES AND RISK OF AN ARTERIAL HYPERTENSION DEVELOPMENT DURING 16 YEARS (1995-2010) IN WOMEN AGED 25-64 IN NOVOSIBIRSK-CITY
}

doi:10.1136/heartjnl-2012-302920a.13

W Gafarov, DO Panov, EA Gromova, IV Gagulin, WV Gafarov. Collaborative Laboratory of Epidemiology Cardiovascular Diseases Siberian Branch of the Russian Academy of Medical Sciences, Novosibirsk

Objectives To study the influence of sleep disturbances (SD) on relative risk of an arterial hypertension ( $\mathrm{AH}$ ) incidence in women aged of 25-64 years during 16 years of follow up in Novosibirsk.

Methods Within the WHO "MONICA-psychosocial" programme random representative sample of women aged 25-64 years who were residents of one district in Novosibirsk, were surveyed in 1994. Questionnaire 'Awareness and attitude towards the health' was used to estimate quality of sleep. From 1995 to 2010 women were followed for 16 years for the incidence of $\mathrm{AH}$. AH was defined as $140 / 90 \mathrm{~mm} \mathrm{Hg}$ or higher and/or reception of antihypertensive drugs. Cox proportional regression model was used for an estimation of relative risk (HR) of $\mathrm{AH}$. Chi-square $\left(\chi^{2}\right)$ was used for assessment of statistical significance between groups. Women having $\mathrm{AH}$ at the baseline were not included in the analysis.

Results $\mathrm{AH}$ was developed in $33.4 \%$ women during 16 years of follow up. SD in studied cohort were revealed in $65.3 \%$ of women. $\mathrm{HR}$ of $\mathrm{AH}$ in women with SD during the first 5 years of study was more than in 4 time higher compared women with good self-estimation of sleep ( $\mathrm{HR}=4.35,95.0 \%$ CI 1.29 to 14,$59 ; \mathrm{p}<0.05)$. With regard to age categories, there was a tendency of increasing AH risk in 35-44 and 55-64 years age groups. During 10 years of study women with SD had 2.7 times higher risk of $\mathrm{AH}(\mathrm{HR}=2.69,95.0 \%$ CI 1.01 to $7.15 ; \mathrm{p}<0.05)$, and there was also a tendencies of higher risk in all age categories with the exception of 25-34 years. We did not have significant risk of $\mathrm{AH}$ during 16 years of follow up in women with $\mathrm{SD}(\mathrm{HR}=1.05,95 \% \mathrm{CI} 0.74$ to 1.48 ; $\mathrm{p}>0.05)$ but there was the tendency of higher risk of $\mathrm{AH}$ in older age groups.

Our findings show AH incidence rates were significantly higher in divorced women with SD compared those who were married with good sleep $\left(\chi^{2}=4.025 \mathrm{df}=1 \mathrm{p}<0,05\right)$. There was tendency of increasing $\mathrm{AH}$ rates in women with higher school education having SD compared those with higher (university) education $\left(\chi^{2}=3.301 \mathrm{df}=1 \mathrm{p}=0,069\right)$ and uncompleted higher or college education $\left(\chi^{2}=2.793 \mathrm{df}=1 \mathrm{p}=0,095\right)$ having good sleep. With regard to 
occupational status, the rate of $\mathrm{AH}$ incidence was higher in middle managers $\left(\chi^{2}=4.340 \mathrm{df}=1 \mathrm{p}<0,05\right)$, managers $\left(\chi^{2}=9.190 \mathrm{df}=1\right.$ $\mathrm{p}<0,01)$, moderate manual workers $\left(\chi^{2}=4.074 \mathrm{df}=1 \mathrm{p}<0,05\right)$ and easy manual worker $\left(\chi^{2}=7.226 \mathrm{df}=1 \mathrm{p}<0,01\right)$ having SD, compared women moderate manual work having good sleep. There was higher rate of $\mathrm{AH}$ in managers $\left(\chi^{2}=7.217 \mathrm{df}=1 \mathrm{p}<0.01\right)$ and easy manual worker $\left(\chi^{2}=5.133 \mathrm{df}=1 \mathrm{p}<0.05\right)$ with $\mathrm{SD}$ compared engineers having good sleep.

Conclusions There is high prevalence of SD in Russian female population aged 25-64. During 16 years of follow up women with SD have significantly higher risk of $\mathrm{AH}$, especially on first 5 years of study. SD associated with higher rate of $\mathrm{AH}$ incidence in divorced women occupied in class of managers and manual work class. 